\title{
Los adolescentes poseen hábitos auditivos de riesgo y signos precoces de disfunción coclear
}

\section{Objetivo}

Explorar la audición de un grupo de adolescentes, determinar el conocimiento sobre los efectos nocivos de los ruidos e investigar el tipo de hábitos auditivos.

Diseño

Estudio de corte transversal con una muestra de conveniencia.

Lugar

Rosario, Argentina

\section{Pacientes}

Se seleccionaron 65 adolescentes de nivel socioeconómico medio que asistían al noveno año de educación médica básica o al tercer año de la enseñanza secundaria. Para ser seleccionados debían contar con la autorización de los padres. Criterios de exclusión: antecedentes otológicos personales y/o familiares; manifestaciones clínicas de patología auditiva; anormalidad de un estudio funcional del oído medio (impedanciometría) normal o de la otoscopía.

\section{Evaluación de factores pronósticos}

Se realizaron evaluaciones auditivas (de la actividad coclear) con otoemisiones por productos de distorsión (DPOAE) en diferentes frecuencias, una audiometría tonal y un cuestionario sobre sus hábitos (concurrencia a locales bailables, uso de auriculares, etc.).

\section{Resultados}

El 63\% de los adolescentes presentó productos de distorsión con amplitudes disminuidas y un $6 \%$ hipoacusias perceptivas. El $83 \%$ refirió conocer los efectos nocivos del ruido como pérdida auditiva y $89 \%$ declaró tener el hábito de escuchar música a elevada intensidad. Se evidenció una disminución auditiva en el grupo que concurría a lugares bailables y tenía el hábito de escuchar música a elevada intensidad (tabla 1).

Tabla 1: resutados de las otoemisiones acústicas por productos de distorsión (DPOE) según el hábito de concurrir a lugares bailables y escuchar música a alto volumen con "walkman" durante más de una hora diaria.

\begin{tabular}{l|c|c|c}
$\begin{array}{c}\text { Evaluación } \\
\text { auditiva }\end{array}$ & $\begin{array}{c}\text { Concuurren } \mathbf{y} \\
\text { tienen el hábito }\end{array}$ & $\begin{array}{c}\text { No concurren y no } \\
\text { tienen el hábito }\end{array}$ & Total \\
\hline Normal & $7(21 \%)$ & 3 & $10(27 \%)$ \\
\hline Lisminuida & $27(79 \%)$ & - & $27(73 \%)$ \\
\hline Total & 34 & 3 & 37 \\
\hline \multicolumn{4}{|c}{$\mathrm{p}=0,015$}
\end{tabular}

\section{Conclusiones}

El alto porcentaje de adolescentes con audición normal, pero con productos de distorsión disminuidos podría estar indicando en forma precoz una disfunción coclear que aún no es evidente en la audiometría tonal y que estaría en relación con los hábitos auditivos de riesgo.

Fuente de financiamiento: Sin financiamiento externo

\section{Comentario}

El daño inducido por el ruido es una causa creciente de consulta clínica en los diferentes grupos etarios. La industrialización y el avance de la tecnología han logrado que la prevalencia de esta patología tenga una curva ascendente. El daño inducido por ruido produce hipoacusias de tipo perceptivo que son irreversibles y muchas veces se acompañan de acúfenos continuos y permanentes de tonalidad aguda y de distintas intensidades y, más raramente, sensaciones vertiginosas. Existen dos tipos de daños inducidos por ruido, aquellos producidos de forma aguda (ej. arma de fuego) y aquellos producidos por la exposición crónica a sonidos de alta intensidad (ej. trabajadores de fábricas o exposición prolongada a música de alto volúmen) como el ejemplo que analiza este trabajo.

La audiometría tonal es un método subjetivo que, entre otras cosas, valora umbrales auditivos entre las frecuencias 125 y $8000 \mathrm{~Hz}$. Las otoemisiones acústicas son un método complementario a la audiometría tonal e informan acerca de la integridad de las células ciliadas externas del órgano de Corti. Sin embargo, cabe aclarar que este estudio no es específico para el diagnóstico de trauma acústico, sino que puede valorar daño coclear en otras patologías del oído interno como, por ejemplo, la ototoxicidad. También puede utilizarse para el diagnóstico diferencial entre lesiones cocleares y retrococleares 0 , entre otras patologías, para la determinación objetiva de hipoacusias psicógenas.

El estudio que comentamos podría haberse completado si a los pacientes se les hubiese efectuado audiometrías de alta frecuencia con el objetivo de determinar los umbrales audiométricos con sonidos puros de frecuencia superior a $8000 \mathrm{~Hz}$ (hasta $20000 \mathrm{~Hz}$ ). Teniendo conocimiento que el daño producido por el ruido comienza a afectar en una primera instancia a la espira basal de la cóclea (donde se encuentran las frecuencias más agudas) se puede concluir que es un método útil para la detección precoz del daño coclear, siendo complementario a las otoemisiones acústicas.

\section{Conclusiones del comentador}

Es necesario crear grupos multidisciplinarios avocados a la prevención de la patología en los distintos ámbitos con distintas lineas de acción: higiene laboral, adecuación de los ambientes a los que concurren los jóvenes (ej. discotecas) control industrial en la fabricación de equipos de sonido. Docentes, audiólogos, otorrinolaringólogos, ingenieros y arquitectos con su trabajo aportaran soluciones para este creciente problema. La experiencia del grupo de Rosario estimula y promueve esta idea.

Carlos Boccio [ Profesor en Medicina y Jefe del Servicio de Otorrinolaringología del Hospital Italiano de Buenos Aires. ]

Boccio C. Los adolescentes poseen hábitos auditivos de riesgo y signos precoces de disfunción coclear. Evid. Actual. Pract. Ambul. 2005;8:172. Comentado de: Fissori L, Janelli A, Casaprina V. Exploración auditiva en adolescentes mediante el uso de otoemisiones acústicas. Arch Argent Pediatr 2003;101(6): 448-453.

\section{Referencias}

1. Werner, Antonio F. Teoría y práctica de las otoemisiones acústicas. Edición del Autor. Buenso Aires, Argentina. Primera Edición 2001.

2. Debas J, Domingues S. Patrones de normalidad para la audiometría tonal de altas frecuencias. Foni audiológica 2002;48(2-3):57-60 